\title{
Construction and Validation of an Educational Technology for Mammary Health Promotion
}

\author{
Izabel Cristina Falcão Juvenal Barbosa, Ana Fátima Carvalho Fernandes, \\ Camila Brasil Moreira, Míria Conceição Lavinas Santos, Altamira Mendonça Félix Gomes, \\ Ivna Silva Andrade, Anna Paula Sousa da Silva
}

Department of Nursing, Federal University of Piauí, Floriano, Piauí, Brazil

Email: izabelbarbosa@ufpi.edu.br

Received 13 October 2015; accepted 8 November 2015; published 11 November 2015

Copyright (C) 2015 by authors and Scientific Research Publishing Inc.

This work is licensed under the Creative Commons Attribution International License (CC BY).

http://creativecommons.org/licenses/by/4.0/

(c) (i) Open Access

\begin{abstract}
Mammary health is issue faced by public health nurses and the science follows new ways into this thematic area of learning course wares. The purpose of this study was to construct and to validate a distance course for mammary health promotion for nurses. Methodological proposal has been composed of five stages: 1) analysis and planning, 2) modeling, 3) implementation, 4) evaluation and maintenance and 5) distribution. A total of nine experts as research population were consulted who were expert judges of nursing, pedagogy and web designer, three of each specific area, which were included in the study. The variables that had concordance index of $50 \%$ were: graphic designer pages favors learning, the user has easy navigation, the learning of the student experience, the environment provides interdisciplinary, content is built on process rather than there is a unique sequence, allows access to the available environment and holds a discussion on the subject. The distance learning course is intended to broaden and to enrich the living spaces and construct their own knowledge, favors interactivity, communication, autonomy and cooperation between the participants and provides access to educational technologies.
\end{abstract}

\section{Keywords}

Distance Education, Educational Technology, Breast Neoplasms, Health Promotion, Nursing

\section{Introduction}

The production of care in clinical practice requires combinations of technology of materials and not material 
dimensions to be resolute. Continuing Education should work to break the hegemonic mode of production of care, reduce the biologicism, promote discussions with professionals and users with regard to extended clinic which includes beyond the disease, the person, the context and to charge for both healing and rehabilitation [1].

Knowing the basic issues of women's health, the ability of breast cancer result in mastectomy, the risk factors and their determinants, the main clinical manifestations due to surgery, the innovations of reconstructive techniques are issues that deserve attention in health for the construction and implementation of a satisfactory physical and organizational infrastructure of health services, of a better quality of care provided by the health staff and nursing professionals, because it is an important public health problem in Brazil [2] [3].

Thus, it is necessary an continuous improvement in breast health, of the professionals of primary care network, as the most effective ways for early detection of breast cancer are clinical breast examination and mammography, which are offered at the entrance door of health services in Family Health Centres.

Some previous studies in the area of women's health and on the problems faced by women who underwent mastectomy and by primary care nurses sought new paths in the theme of distance education. From the foregoing the objective of this study is to design and to validate an updating distance course on breast health for nurses.

\section{Method}

\subsection{Participants}

The study sample was composed of nine specialist judges in nursing, pedagogy and web designer, three of each specific area, who evaluated the distance course on breast health, in the educational and pedagogical technique, communication/social and administrative perspectives, as showed in Table 1.

\subsection{Instruments}

To collect data, two instruments were used by questionnaire, one to evaluate content, technique, pedagogicaldidactic, communicational and social that included three (3) items, distributed in 24 criteria where each item consisted of five categories of answers, like the Likert scale: (TA) totally agree; (PA) partially agree, (U) undecided, (TD) totally disagree e (PD) partially disagree. The other instrument for the assessment of the technical and administrative perspective contained two (02) items distributed in 50 criteria, where each item presented a value scale with five response categories: (1) poor, (2) regular, (3) good, (4) very good and (5) Excellent.

\subsection{Data Analysis}

The Statistical Package for the Social Sciences 15.0 software was used for statistical analysis. The significance level for all analyses was set at 5\%. For descriptive analysis, data were organized into categorical and numerical variables. For categorical variables, the absolute frequencies were used, the percentages and confidence interval (95\%) and for numerical variables the mean, median and standard deviation were used. The Bloom's Taxonomy was used to guide the development of educational materials and assist in the evaluation of the teaching-learning process [4].

\section{Results}

For the elaboration of educational material developed, Curso de Atualização em Saúde Mamária-CASM (a continuing course on breast health) $100 \%$ compliance of the judges was obtained in full agreement as to the question referred to the compatibility of the information with the objectives previously established, $66.7 \%$ reported they strongly agreed that the contents of the references add value to information and only (2) 33.3\% agreed partially. When analyzing the topic for the organization of information clearly to facilitate learning (5) $83.3 \%$ of the judges completely agreed and (1) $16.7 \%$ agreed partially.

Regarding the content, (4) $66.7 \%$ partially agreed that the content is appropriate to users, (2) $33.3 \%$ agreed completely, (5) $83.3 \%$ of the judges partially agreed with the consistency of content (4) $66.7 \%$ fully agreed with the content stream, (5) 83.3\% stated that they totally agree with the objectivity of content.

As for the pages graphic designer promoting the learning of users and the facility for users to navigate on the page, $50 \%$ of the judges completely agreed, and $100 \%$ totally agreed that the pictures and images add knowledge, (5) 83.3\% said the images and prints match those texts. Concerning the arrangement of modular units 
Table 1. The demographic and other characteristics of the specialists.

\begin{tabular}{|c|c|c|c|}
\hline \multirow{2}{*}{ Sociodemographic information } & \multicolumn{3}{|c|}{ Value } \\
\hline & Frequency & $\%$ & Mean \\
\hline \multicolumn{4}{|l|}{ Age } \\
\hline $28|-| 40$ & 4 & 44.4 & \multirow{3}{*}{$\begin{array}{c}42 \\
\mathrm{SD}^{\mathrm{a}}= \pm 11.02\end{array}$} \\
\hline $41|-| 51$ & 3 & 33.3 & \\
\hline $52|-| 62$ & 2 & 22.2 & \\
\hline \multicolumn{4}{|l|}{ Marital Status } \\
\hline Single & 1 & 11.1 & \\
\hline Married & 4 & 44.4 & \\
\hline Separated/Divorced & 1 & 11.1 & \\
\hline Did not answer & 3 & 33.3 & \\
\hline \multicolumn{4}{|l|}{ Titles } \\
\hline Specialty & 3 & 33.3 & \\
\hline Master & 2 & 22.2 & \\
\hline Doctorate & 3 & 33.3 & \\
\hline Pos Doctorate & 1 & 11.1 & \\
\hline \multicolumn{4}{|l|}{ Graduation year } \\
\hline $1975|-| 1984$ & 1 & 11.1 & \\
\hline $1985|-| 1994$ & 3 & 33.3 & \\
\hline $1995|-| 2004$ & 3 & 33.3 & \\
\hline$\geq 2005$ & 2 & 22.2 & \\
\hline \multicolumn{4}{|l|}{ Graduation period (year) } \\
\hline $4|-| 13$ & 5 & 55.6 & \\
\hline $14|-| 23$ & 2 & 22.2 & \\
\hline $24|-| 33$ & 1 & 11.1 & \\
\hline $34|-| 43$ & 1 & 11.1 & \\
\hline \multicolumn{4}{|l|}{ Experience in EAD } \\
\hline student & 2 & 22.2 & \\
\hline tutor & 4 & 44.4 & \\
\hline know it & 2 & 22.2 & \\
\hline work with it & 1 & 11.1 & \\
\hline \multicolumn{4}{|l|}{ Period of experience in EAD } \\
\hline $0|-| 4$ & 6 & 66.7 & 4.0 \\
\hline $5|-| 9$ & 2 & 22.2 & $\mathrm{SD}^{\mathrm{a}}= \pm 3.2$ \\
\hline Did not answer & 1 & 11.1 & \\
\hline
\end{tabular}

a. $\mathrm{SD}( \pm)=$ Standard Deviation.

content contributes to the user learning (5) 83.3\% of the judges completely agreed.

When analyzing the reliability of provided information and, if they are updated and add knowledge about breast cancer, $66.7 \%$ of the judges fully agreed that the sources used in the course construction are credible and are free of typographical and grammatical errors.

What concerns the description of the learning assessment, $50 \%$ of nursing and pedagogy judges totally agreed that the course allows learning from the user experience, $66.7 \%$ of the judges completely agreed that evaluations at the end of each module are useful for reviewing the course material. 
As noted, $66.7 \%$ of the judges fully agreed that evaluations at the end of each module are useful for reviewing the course material. In this sense it is noteworthy that at the end of each CASM modular unit there are multiple choice questions with only one correct answer for each question, with mutually option excluded. There are no restrictions and limits on the maximum number of attempts to the student to get the correct answer.

As the paradigm of interactional and constructivist learning (4) 66.7\% of the judges completely agreed and (2) $33.3 \%$ partially agreed. With regard to the question of focus on learning-based, autonomy and respect for the pace of development system (4) $66.7 \%$ of the judges completely agreed and (2) $33.3 \%$ partially agreed.

With regard to collaboration (3) $50 \%$ of the judges totally agree and (3) $50 \%$ partially agree, (6) $100 \%$ of the judges fully agreed that the system focus is based on the development of skills and abilities and the construction of knowledge, (5) $83.3 \%$ of the judges fully agreed that the focus of the system is in cooperation.

The learning environment was considered by the judges participative and centered on interaction. It promotes the exchange of experiences and the construction of knowledge, is cooperative and provides an interdisciplinary environment.

Regarding the description of the learning environment methodology, $83.3 \%$ of judges fully agreed that the methodology is cooperative, $66.7 \%$ completely agreed in the question referred to the methodology being interactive and problematizing and based on the identification and resolution of problems.

It was found that $100 \%$ of the judges completely agreed that the assessment is formative, continuous and allows troubleshooting situations, study of cases highlighted in the spaces of interaction. The evaluation is focused on the process, observation and development and values the interaction to the understanding and application of concepts.

It was observed that all the judges fully agreed that autonomous learning allows students to access their own sources expanding their learning. As regards the reflection item, $83.3 \%$ of the judges fully agreed with this topic stating it allows teachers to assist students on feedback from their actions with the goals.

Regarding the description of the information space and sources of trading of the learning environment, 83.3\% of judges completely agreed it allows the access to general information about the course and communities, $100 \%$ completely agreed in the question regarding the possibility of holding a participatory and flexible planning and define responsibilities and mutual agreements.

It is observed that $83.3 \%$ of the judges strongly agreed that communication tools are integrated, $66.7 \%$ state that they fully agreed that the tools (e-mail and conferencing) allow one to attach and extract files.

In items related to the learning objectives being specified and could be recorded on the basis of conversation and the question that allows access within the same environment the available material and conduct a discussion on the subject, $50 \%$ of the judges agreed completely. In the question referred to allow the objectives being shown with their learning topic, 83.3\% judges completely agreed that both teacher and student conceptions are affordable for everyone, $100 \%$ of completely judges agreed it enables cooperative goal setting learning and (4) $66.7 \%$ of judges completely agreed it enables action, production and receiving feedback on the defined objectives.

Finally, a modular structure presented in four learning modules which includes fifteen thematic units, containing items and sub-items was obtained (Table 2).

\section{Discussion}

The biggest challenge for a constructivist and social interactionist practice requires a break of the teaching and students posture from the traditional teaching practice. The pedagogical proposal should be challenging and problematizing and should involve the participating subjects in the teaching and learning process [5].

The specialized judges in nursing and pedagogy rated and mostly (65\%), completely or partially agreed the educational proposal included the criteria items of the technical, pedagogical educational, communicational and social perspective of the distance education in the breast health.

In the technical perspective the items that obtained more than $65 \%$ of satisfactory evaluation were: authority; presentation, organization, evaluation, coherence, sequence, objectivity and reliability of the contents; used tools and evaluation of learning. Except for this last aspect, "assessment of learning” whose topic referring to promote learning from the user experience, evaluation obtained less than $65 \%$.

In the pedagogical didactic perspective the topics also obtained top rating to $65 \%$, ranging from fully and partially agree on the following aspects: paradigm of interactionist and constructivist learning, focus on learning-based system, autonomy and respect for the pace of development, development competences and skills, 
Table 2. Educational content of each class in the CASM.

\begin{tabular}{|c|c|}
\hline Module & Frequency \\
\hline I & $\begin{array}{l}\text { Class } 01 \text { - Cancer: Historical background and definitions } \\
\text { Class } 02 \text { - Breast anatomy } \\
\text { Class 03-Cancer pathophysiology } \\
\text { Class 04-Cancer epidemiology in Brazil and in the world } \\
\text { Class } 05 \text { - Public policies of relevance to the health of the woman related to breast cancer control }\end{array}$ \\
\hline II & $\begin{array}{l}\text { Class } 01 \text {-Risk factors for breast cancer } \\
\text { Class } 02-\text { Modification related to breast benign lesions } \\
\text { Class 03-Main malignant changes in the female breast } \\
\text { Class } 04-\text { Special situations for tracking the breast cancer } \\
\text { Class 05-Degree of recommendation }\end{array}$ \\
\hline III & $\begin{array}{l}\text { Class } 01-\text { National strategies for tracking, early detection and diagnosis of breast cancer } \\
\text { Class } 02-\text { Methods of treatment of breast cancer }\end{array}$ \\
\hline
\end{tabular}

cooperation and the construction of knowledge.

Other criteria included in the pedagogical didactic perspective, were also evaluated positively, more than $65 \%$, by specialist judges, namely: participatory learning environment, cooperative and focused on interaction, promotes the exchange of experiences and the construction of knowledge, teaching is based on the interaction, cooperation and problematization and part of what students already know, the methodology is cooperative, interactive, problematizing and based on the identification and resolution of problems and the assessment is formative, continuous and allows the solution of problem situations, case studies emerging in the interaction spaces favoring autonomous learning.

The communicational and social perspective and the items that obtained more than $65 \%$ of satisfactory assessment by specialist judges who fully or partially agreed were: information space and sources of trading of the learning environment, the discursive tools, interaction and interactivity of the course, student and teacher profiles.

The web design specialists judges mostly (65\%) attributed concept, good, very good and excellent in the following aspects of the technical and administrative perspective, namely: technical support, management and environment management tools, management tools of communities, professor and user authoring tools, the individual and community area tools, service tools, synchronous and asynchronous tools and assessment tools.

On the foregoing facts it is considered that this educational technology successfully meets and may be available for the formation of the Family Health Strategy nurses regarding the theme in breast health, drawing on the pedagogical framework of Vygotsky social interactionist design and the Meaningful Learning Theory of David Ausubel [6].

\section{Conclusions}

The continuing health education has emerged as a theoretical and pedagogical model to generate changes in the qualification and performance of professional and in-service training for health workers whose needs are detected in their work processes of health professionals which are urged to reflect and rethink their practice by modifying its context and professional life.

It is noteworthy that the results achieved in the construction and validation of the distance course in breast health inserted in the virtual learning environment of breast-AVAPMAMA follows the calling of the National Curriculum Guidelines for Undergraduate Nursing Course and the National Policy on Continuing Education in Health, when it offers a new way of training the health professionals, specifically nurses, posing as active, critical and reflective subject in learning process and the educator/teacher as mediator/facilitator of this process.

\section{References}

[1] Aguiar, R.V. and Cassiani, S.H.B. (2007) Development and Evaluation of a Virtual Learning Environment in Professional Nursing Courses. Revista Latino-Americana de Enfermagem, 15, 1086-1091. http://dx.doi.org/10.1590/S0104-11692007000600005

[2] Barbosa, S.F. and Sasso, G.T.M.D. (2007) Internet e saúde: Um guia para os profissionais. Nova Letra, Blumenau.

[3] Bergmann, A., Mattos, I.E. and Koifman, R.J. (2004) Diagnóstico do linfedema: Análise dos métodos empregados na 
avaliação do membro superior após linfadenectomia axilar para tratamento do câncer de mama. Revista Brasileira de Cancerologia, 50, 311-320.

[4] Bloom, B.S., Engelhart, M.D., Furst, E.J., Hill, W.H. and Krathwohl, D.R. (1972) Taxonomia de objetivos educacionais: Domínio cognitivo. Editora Globo, Porto Alegre.

[5] Falkembach, G.A.M. (2005) Concepção e desenvolvimento de material educativo digital. Revista Novas Tecnologias na Educação, 3, 1-15.

[6] Levy,L.F. and Santo, A.O.E. (2006) A psicologia vygotskyana e uma alternativa transdisciplinar. Acta Scientiae, 8, 5-24. 